\title{
From excavation data to HBIM environment and cloud sharing: the case study of Domus Regia, Sacraria Martis et Opis (Roman Forum, Rome - Italy)
}

\author{
Filippo Diara ${ }^{1 *}$, Fabio Cavallero ${ }^{2,3}$ \\ ${ }^{1}$ Politecnico di Torino, Department of Architecture and Design, Viale Mattioli 39, 10129 Torino, Italy \\ filippo.diara@polito.it \\ ${ }^{2}$ Sapienza University of Rome, Department of Ancient World Studies, Piazzale Aldo Moro 5, 00185 Roma, Italy \\ fabio.cavallero@uniroma1.it \\ ${ }^{3}$ Italian Archaeological School of Athens, Odos Parthenonos 14, 11742 Atene, Greece
}

KEY WORDS: Archaeology, Data management, Documentation, HBIM, Open source, Roman Forum

\begin{abstract}
:
The importance of the Digital Atlas of Rome has been crucial in order to map and analyse archaeological remains of the monumental layout of ancient Rome, enhancing the contextual connections and easing the interpretation the original city-scapes and architecture. Then, the main goal has been twofold: to recompose the archaeological framework of available knowledge and to propose reconstructive hypotheses of ancient buildings. The Domus Regia, Sacraria Martis et Opis is one of these important buildings, excavated and documented over the years. In this regard, the archaeological data and the hypothetical reconstruction of the Domus Regia have been the focus of this project. In fact, the beginning of this integrative project is due to the desire to investigate how different methodology and workflows can be combined synergistically in a HBIM platform in order to ease data documentation, management and dissemination. Informative platforms and cloud solutions may be the proper solution for integrating metric data with semantic archaeological data, including and updating previous analyses. For this reason, the Domus Regia data has been managed inside a FOSS HBIM platform (FreeCAD), which was designed as a dynamic environment for modelling parametrically the ancient building and connecting related IFC objects with semantic information. Then, the resulted HBIM model has been valued and shared by using BIMData cloud platform and tested inside another environment developed ad-hoc for archaeological purposes.
\end{abstract}

\section{INTRODUCTION}

This project, still in progress, focuses on how archaeological analysis and its 2D informative system can be related to an open source HBIM solution in order to obtain an informative environment, including different types of data and facilitates management and revisions processes. The project is therefore affected by the desire to integrate different methodologies and academic frameworks for increasing knowledge accessibility.

This is the basis of a new collaboration between Sapienza University of Rome and Politecnico di Torino (DAD department) for the data integration referred to an important religious building inside the Roman Forum (Rome): the Domus Regia, Sacraria Martis et Opis. The analysis of this building is part of another important project: the Digital Atlas of Rome designed (through a 2D informative system) for understanding the historical evolution of the landscape of the city of Rome as well as for proposing reconstructive hypotheses (Carandini et al., 2017a; 2017b).

Moreover, this research is based on what Historic Building Information Modelling (Murphy et al., 2009; 2013) methodology and FOSS (Free and Open Source solution) instruments can offer to archaeology (Diara et al., 2020), creating an informative and dynamic system starting from existing data of Domus Regia (Figure 1).

The importance of HBIM methodology for archaeology experienced an exponential growth due to its possibilities regarding interactive documentation and a new type of involvement for professionals. Then, cloud platforms for sharing knowledge prove to be necessary for this purpose. In this regard, HBIM projects for archaeology require a deep analysis (through a solid framework) especially for monitoring processes, further studies as well as consolidation / restoration operations across semantic and ontological data (Messaoudi et al., 2018; Trizio et al., 2019).

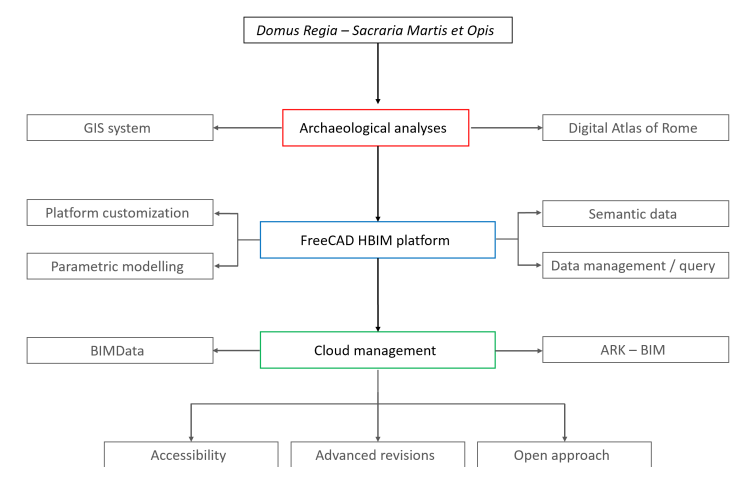

Figure 1. Main steps related to the project workflow: from archaeological analyses to HBIM environment and data management via cloud solutions.

\section{ATLAS OF ROME AND DOMUS REGIA}

The Digital Atlas of Rome project, conducted by Sapienza University of Rome, started twenty years ago with the aim of reconstructing the evolution of the landscape of the city of Rome and its suburbium. The approach is systematic, contextual and diachronical, and the project developed as GIS 
based since the beginning. Main goal is to map and analyse the remains of the urban and monumental layout of the city, enhancing the contextual connections which, although broken and disconnected through time, can be joined together again in order to reconstruct and interpret the original city-scapes and architecture, and to trace the city landscape narrative (Carandini et al., 2017a).

Strong attention is paid to the creation of detailed vector shapes, representing all the structures and some finds discovered up to now, mapped in real absolute coordinates and not symbolic. Vector layers produced were joined with a PostGRES relational database. The large geographical archive was then moved to an ESRI environment (GIS) for analyses and thematic mapping to get finally into a WEB interface to disseminate the data to the larger public.

The project aims to manage the heterogeneous sources of information which would allow to reconstruct the landscape and built environment's contextual links, often interrupted by human and natural actions through time. This will provide for the systematic collection - so far never attempted - of all the archaeological evidence datable to IX cent. BC to VI cent. AD. By analysing archaeological evidences, we can proceed to a progressive logic-spatial process of the known evidence, at different levels. Based on the collected data, main goal was twofold: to recompose a framework of available knowledge based on different sources of information that allows to analyze and systematically investigate what is known and what is poorly known; to propose reconstructive hypotheses, based on all the different classes of documents that allow to integrate the poorly known parts of the ancient monuments, to try to define hypotheses about the lost or missing parts of what is known, in search of a progressive plausibility.

\subsection{Domus Regia, Sacraria Martis et Opis}

These analyses have been conducted also for the Domus Regia, Sacraria Martis et Opis which is one of the most important religious buildings of the Roman Forum, excavated and documented over the years.

The area of the actual religious building, the fanum, was originally designed at the time of Lucius Tarquinius Priscus, ruler of Rome (Carandini et al., 2017b): indeed, beyond the vicus vestae was built the sacred building which now hosts the Sacraria Martis et Opis (furnishing and ornaments related to Mars and Ops). Before this place, these sacred objects were probably located inside the royal domus referred to the palace of the first Latins and Sabines kings, but, over the time, the sacraria were moved because of incompatibility of duties (Carandini et al., 2017b).

The collected archaeological data led to a hypothetical reconstruction of the religious building. According to excavated data and remains, the Domus Regia had an east-west orientation with a monumental entrance which included a staircase and columns. The internal area of the building was designed to have an open courtyard which probably included the ritual altar. On the south side of the courtyard there were the other internal rooms, including the sacred space of Mars (with a fireplace) and Ops.

The archaeological data and the hypothetical reconstruction of the Domus Regia have been at the centre of this project.

\section{HBIM ENVIRONMENT}

The platform used - FreeCAD version 0.19 - is strictly linked to one of the main goals of the project: to create and manage a HBIM projects for archaeology in the smartest possible way in order to ease collaborations and future analyses. For this reason, the adoption of FOSS solutions has proved to be a valid instrument for Heritage assets documentation through dynamic and customizable tools (Diara et al., 2019; 2020). In fact, FreeCAD has become a complete BIM software after the implementation of required instruments like $B I M$ workbench, DynamicData workbench, Reporting workbench, SQL parser library, IFCOpenShell library. Nevertheless, main instruments and commands of DRAFT, PART, ARCH, BIM have been grouped inside a custom workbench in order to obtain an easiest access to fundamental functionalities.

\subsection{Parametric modelling}

The parametric modelling step is crucial for HBIM projects. According to different historical contexts, modelling approaches should be carefully planned also depending on LODs (levels of details) which should be achieved and the complexity of architectural elements (Fai et al., 2014; Brumana et al., 2018; Banfi F., 2019; Sammartano et al., 2021). In fact, in the same way of scan-to-BIM workflow, this project has been affected by an initial choice regarding modelling details: the Domus Regia modelling has been conceived as the parametric restitution of archaeological evidences and of the hypothetical reconstruction. The modelling of shapes and elements occurred for the purpose keeping archaeological and architectural details as well as preserving the conceptual model hypothesis.

This step started from 2D metric data referred to the archaeological plan of the building and the reconstruction plan; a section (east-west) and two elevations (front view and north view) of the reconstructed building (Figure 2). This data was fundamental in order to compare 2D digital metric data (archaeological remains and reconstructions) to stratigraphic analysis and other paper-based information produced over the years.

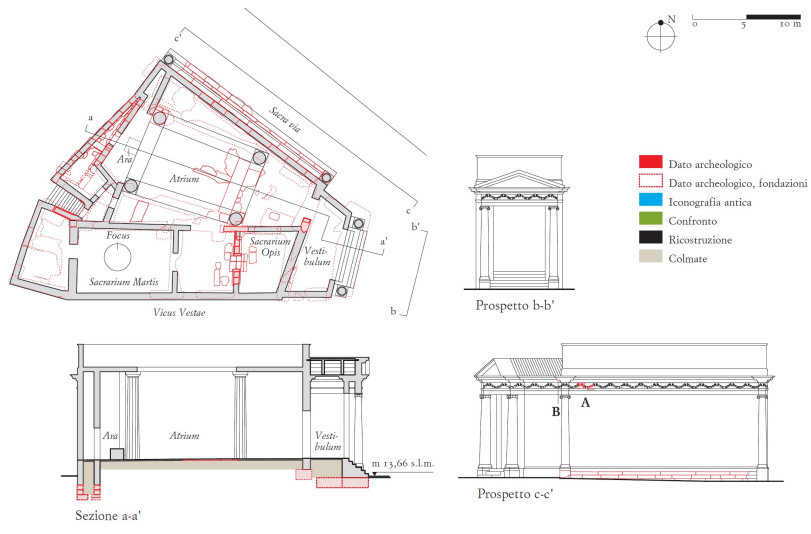

Figure 2. 2D metric data related to Domus Regia: archaeological and reconstruction plan, two fronts, a section.

This vectorial data (CAD) has been imported inside FreeCAD as DXF drawings and then the geometric primitives extraction and interpretation started, based on architectural elements of the hypothetical reconstruction and the archaeological remains of the building (Figure 3 ).

The first step regarded the parametric modelling of archaeological evidences, starting from the archaeological plan: from remains (stone elements) to foundations evidences (visible in plan, sections and elevations). Stone elements are principally referred to walls and internal flooring remains and for this reason they show two different grades of elevations in relation to the level of the building: $+0,00 \mathrm{~m}$ the perimetral walls remains 
and $+1,75 \mathrm{~m}$ the internal flooring remains. Then, the parametric modelling of archaeological evidences has been designed in the simplest way possible: wired profiles of archaeological remains have been used as basis for solid extrusions, keeping stone and foundations finds as they have been documented (Figure 4).

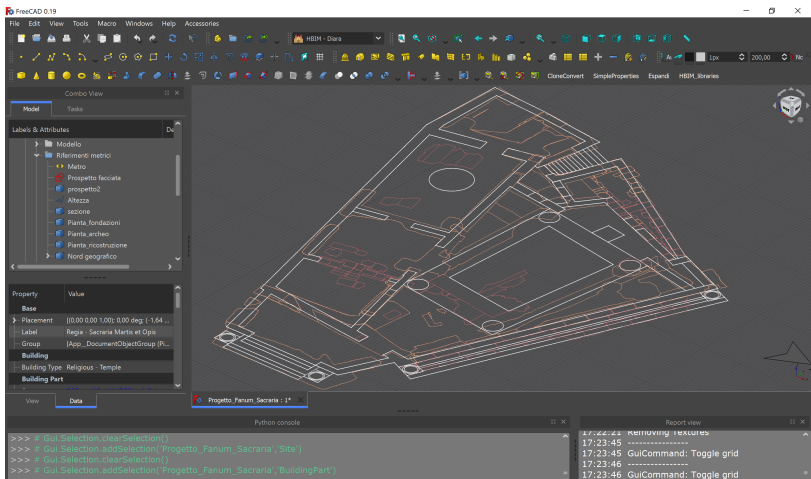

Figure 3. 2D vectorial data imported inside FreeCAD: archaeological and reconstruction (white) plans.

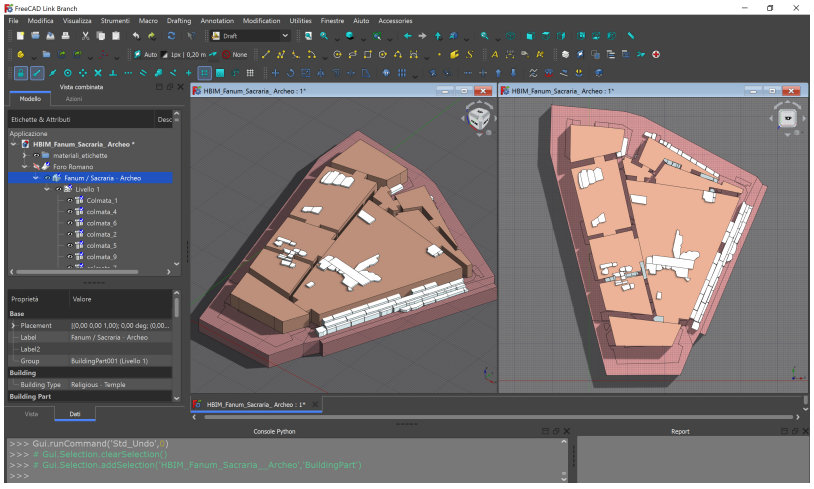

Figure 4. Parametric model of the archaeological evidences of the excavated Domus Regia.

Next modelling step regarded the hypothetical reconstruction of the religious building. Inside the platform, the parametric modelling of principal architectural elements has been performed by creating simple parametric shapes as cubes, cylinders, torus, cones and so on. Some elements have been obtained from the union, intersection or subtractions of other objects. The elements deducible in the plan and in the elevations have been reconstructed by extruding (according to real measurements) wired profiles drawn directly on 2D CAD data. Going deeper, perimetral and internal walls reconstruction started from 2D closed wires (with flat faces) drawn on the original plan, redesigned with sketches and wires. Closed wires have been set as parametric walls (ARCH workbench) setting the height according to measurements extrapolated from 2D elevations. In this way simple wires become parametric walls (ifcWall) with dynamic metric properties, such as wall height and width (Figure 5).

The doric column has been decomposed into four simplified objects, starting from PART modelling tools: the column shaft was created from a parametric cone (first radius $0.58 \mathrm{~m}$; second radius $0.46 \mathrm{~m}$; height $7.59 \mathrm{~m}$; angle 360 degree); continuing upwards, a small parametric torus was created in order to obtain the astragal (first radius $0.46 \mathrm{~m}$; second radius $0.03 \mathrm{~m}$; first angle -180 degree; second angle 180 degree; third angle 360 degree); the echinus was modelled as a parametric cone (first radius $0.46 \mathrm{~m}$; second radius $0.66 \mathrm{~m}$; height $0.26 \mathrm{~m}$; angle 360 degree); the final abacus has been obtained from a simple cube (length
$1.41 \mathrm{~m}$; width $1.41 \mathrm{~m}$; height $0.25 \mathrm{~m}$ ). The doric column measurements have been taken from metric data related to eastwest section. The obtained column served as a basis for the others, set as ARCH structure and ifcColumn.

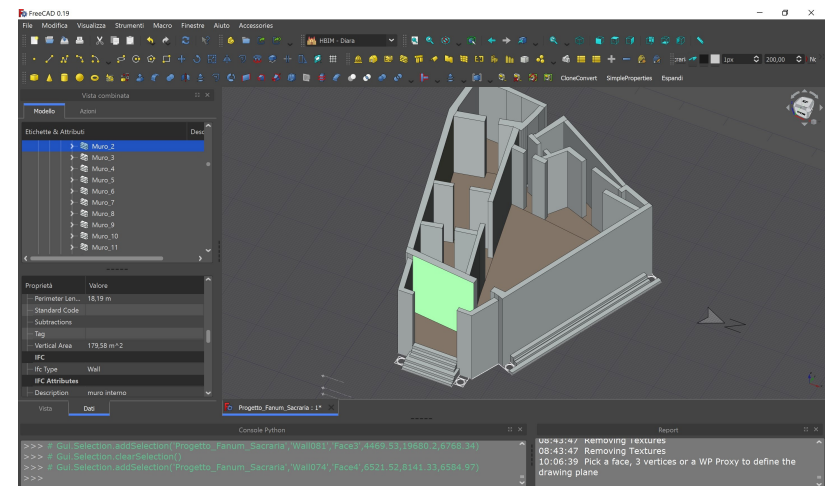

Figure 5. Detail on parametric walls obtained by extruding 2D wires from the ground plan.

Columns of ionic order have been designed in the simplest possible parametric way. Starting from the bottom, the column base has been obtained from a parametric cube (length $1.02 \mathrm{~m}$; width $1.02 \mathrm{~m}$; height $1.00 \mathrm{~m}$ ). The decorative base of the column has been designed simplifying the scotia, astragal, collar into three parametric cylinders, decreasing in height and radius.

Then, as terminal part of the decorative base, three torus have been modelled, two of equal dimensions (first radius $0.36 \mathrm{~m}$; second radius $0.064 \mathrm{~m}$; first angle -180 degree; second angle 180 degree; third angle 360 degree) and a third that overlaps with these two on the middle (first radius $0.39 \mathrm{~m}$; second radius $0.066 \mathrm{~m}$; first angle -180 degree; second angle 180 degree; third angle 360 degree). Then, the shaft was created from a parametric cone (first radius $0.39 \mathrm{~m}$; second radius $0.32 \mathrm{~m}$; height $6.21 \mathrm{~m}$ ); the terminal part of the shaft has been designed with two alternate cylinders and torus.

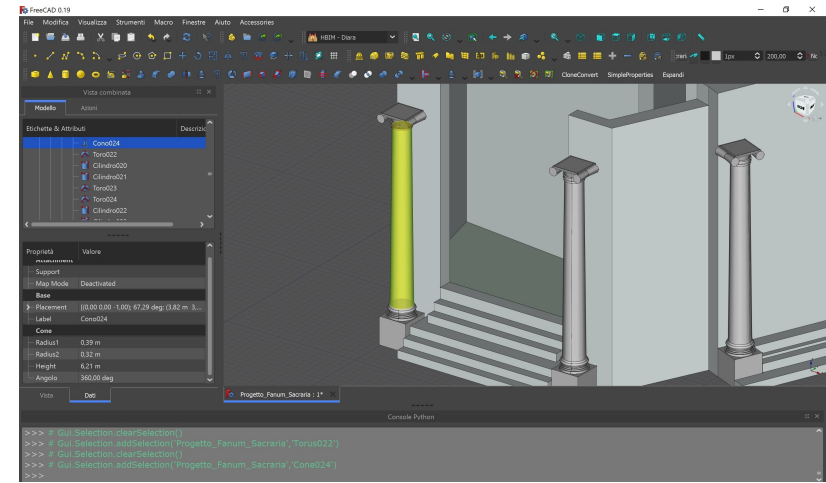

Figure 6. Detail on parametric cone related to the shaft of the ionic column on the entrance.

The ionic capital has been extremely simplified in its geometry and decorations. It has been subdivided into five parametric elements: a parametric cone (first radius $0.32 \mathrm{~m}$; second radius $0.39 \mathrm{~m}$; height $0.22 \mathrm{~m}$; angle 360 degree) and four horizontal mirrored cones and symmetrically modelled have been used as the volume of the ionic volutes (first radius $0.11 \mathrm{~m}$; second radius $0.15 \mathrm{~m}$; height $0.48 \mathrm{~m}$; angle 360 degree).

The abacus has been designed as two overlapped parametric cubes, which differ in length, width and height. As for the doric columns, the obtained column served as a basis for the others, set as ARCH structure and ifcColumn. 
As regard the covering of the religious building, the flat surface related to the roof has been modelled extruding the real dimension of the possible covering and making slices for the impluvium (watershed). The tympanum has been created by merging and slicing flat surface with a particular inclination. Finally, these objects have been classified as ifcRoof elements. The parametric modelling of the Domus Regia generated dynamic elements. Changing primitive shapes profiles, height, and thickness values (width) the platform automatically will update the element on the 3D space and other resulted metric data: horizontal and vertical area, perimeter length, objects face area, objects volume, specific height and width.

The parametric modelling has revealed essential especially in this type of analysis: hypothetical reconstructions of a specific historical period of a building require constant updates on hypotheses about architectural elements, mainly concerning their geometric shapes and dimensions. In this regard, the Domus Regia parametric model could be always upgradable depending on latest researches and hypothesis.

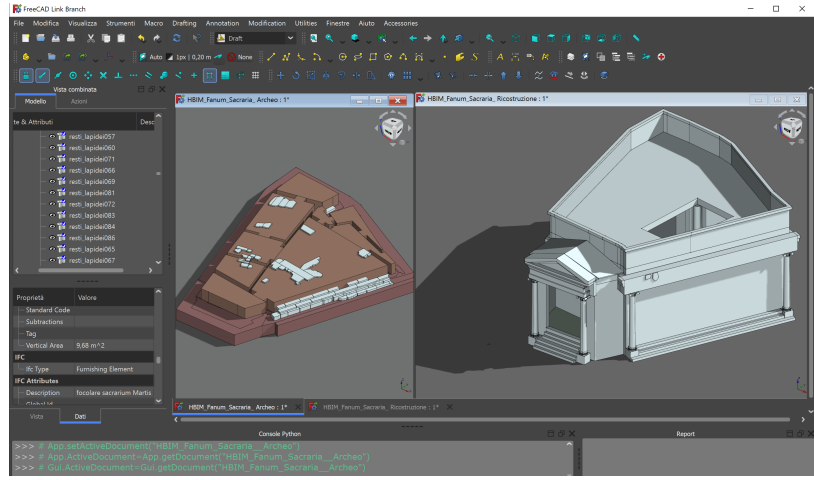

Figure 7. Parametric models of the Domus Regia Archaeological situation (left); hypothetical reconstruction (right).

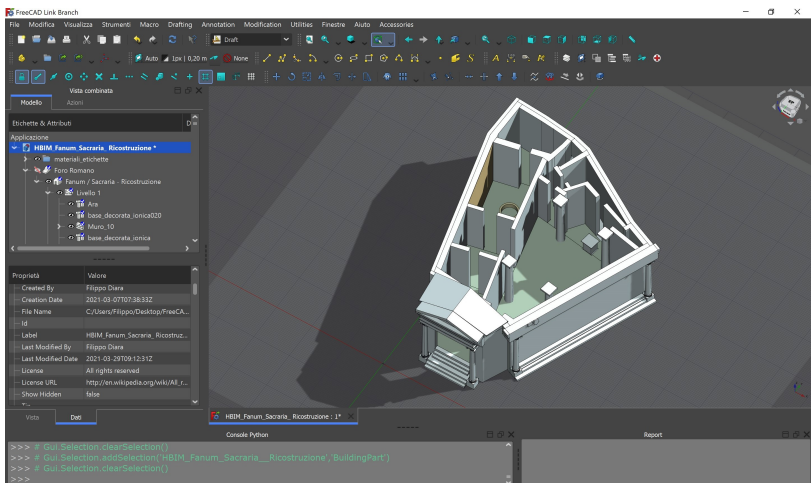

Figure 8. Hypothetical reconstruction model with internal subdivision details: in particular the courtyard with columns; the Sacrarium Martis with fireplace.

\subsection{Semantic data}

After the parametric modelling step, next step has been the preliminary inclusion of semantic information. This operation should be carefully planned with the same importance as parametric modelling, avoiding entering unnecessary data. For this reason, notwithstanding the inclusion of information is crucial as well as mandatory, the amount of archaeological data could make the whole process complex (Croce et al., 2021).

Inside the FreeCAD platform, the objects classification was the first semantic operation to be performed: this operation allows parametric objects to be transformed into architectural elements with semantic attributes and classification (Wall, Column, and so on). In fact, in addition to metric data and generative geometries (construction base), the implemented semantic data is referred to main properties of IFC objects: descriptions, material information, objects types, identification codes, semantic tags.

These last two semantic attributes can be managed for including references related to stratigraphic analysis and for tagging particular textual information, e.g. historical interpretation. The creation of custom attributes and data containers is therefore possible.

Moreover, the semantic sphere of the Domus Regia has been implemented by deeper semantic information: drawings and archaeological charts, iconographic references, essential bibliographic information, photographic references of archaeological finds. These important data, thanks to FreeCAD database and addons, have been dynamically linked to related parametric objects: for example, the two pieces of archaeological findings related to the architectural frieze (north front) have been semantically implemented with photographic references, drawings and iconographic data. At the same time, the hypothetical reconstruction related to a wall inside the Sacrarium Martis and the hypothesis regarding an archaeological find have been dynamically linked to the parametric wall of the sacred area. These inclusions are available on the property menu of the parametric object as linked references (Figure 9).

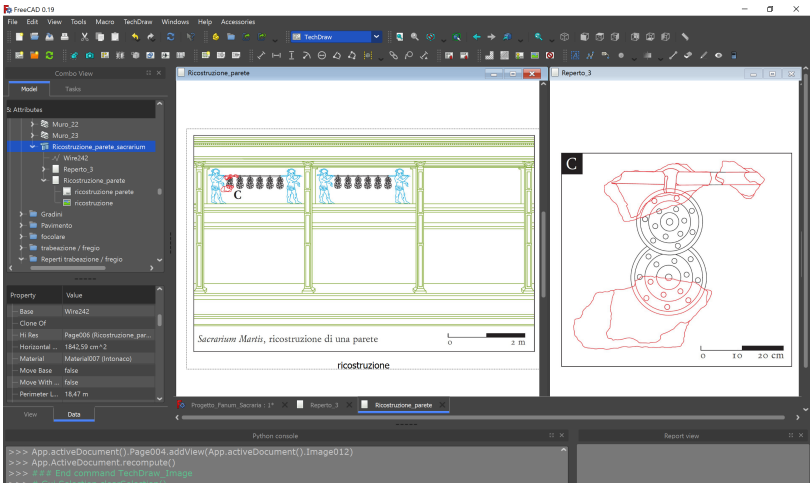

Figure 9. Sacrarium Martis area: wall reconstruction and hypothesis of an archaeological find. Images linked to parametric model of the Sacrarium Martis wall.

This data is crucial in order to investigate Domus Regia information through critic query processes, a mandatory step for HBIM projects. This process has been conducted by a specific query language: Standard Query Language (SQL). Despite testing the possibility of performing SQL queries directly on Python console by exploiting the $S Q L$ parser library, investigations have been carried out especially by designing SQL statement inside the Reporting workbench, which offers a more user friendly experience on querying data (Figure 10).

In this way, apart from the property menu, semantic information of architectural elements can be easily accessed by designing simple or relational query.

Being a work in progress project, at the moment the informative platform includes the archaeological data just described (especially archaeological evidences, iconographic references, reconstructions). However, the internal database of FreeCAD, and then all semantic data, can be implemented after further analyses or modified due to revisions. In this way, the complete stratigraphic analysis of the religious building can be implemented also for a deep comparison among historical interpretation and $3 \mathrm{D}$ restitution. 


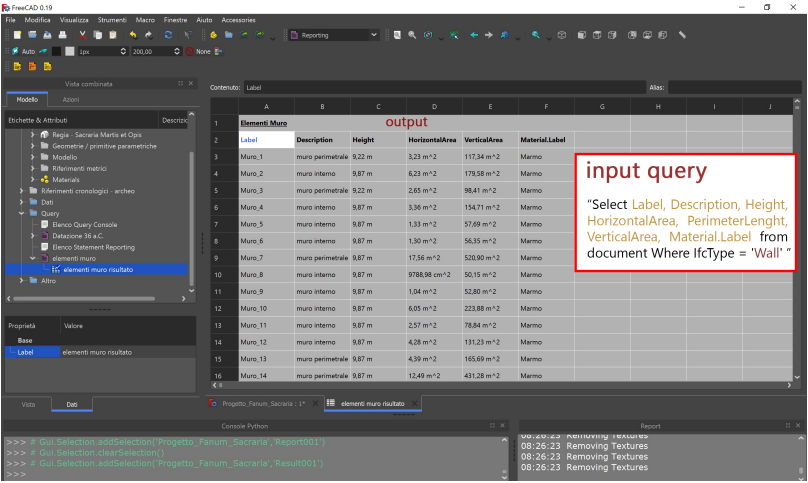

Figure 10. SQL query related to principal information (description; height; areas; materials) of Wall elements of the Domus Regia

\section{CLOUD DATA SHARING}

The HBIM platform created with FreeCAD has been fundamental in order to hold different data together (from vectorial $2 \mathrm{D}$ to parametric $3 \mathrm{D}$ and semantic data) for local investigation and management (Diara et al., 2019; 2020). However, HBIM projects require an advanced sharing via open and web platform in order to ease the collaborative approach between different professionals, also for spread semantic knowledge via cloud environment (Quattrini et al., 2017; Logothetis et al., 2018).

As result, once completed the HBIM platform, the next step has been the cloud sharing of the project through the BIMData platform, a free (and open) solution for the online management. Briefly, BIMData (https://bimdata.io) is a smart web platform designed for collaborators and partners of a BIM project (Figure 11).

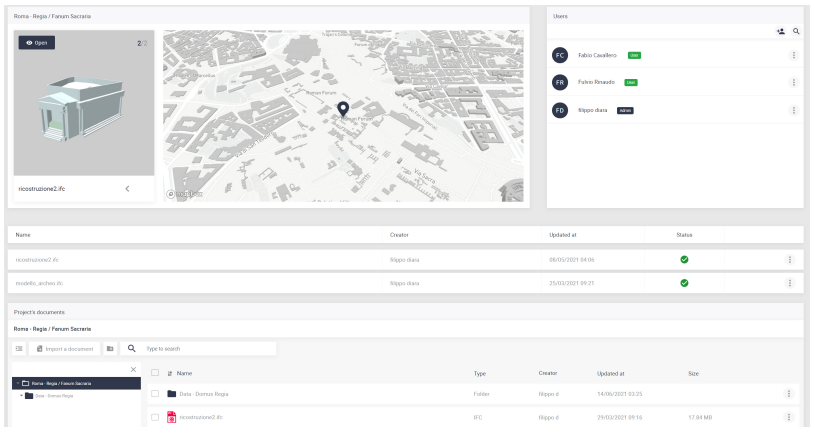

Figure 11. BIMData platform interface: the viewer to the left; location at the center; users to the right; upload version and data below.

This solution allows to handle files, users and workflow: IFC files can be explored and investigated through their structure and properties (as well as other uploaded files).

The HBIM models of the Domus Regia has been uploaded on a personal cloud of BIMData (preserving all the attributes set within FreeCAD), in addition to external semantic data (PDFs, images and datasheets). Two models have been imported: the model referred to the excavated situation and the reconstruction of the Fanum / Sacraria. Both models preserve all the attributes (from metric to semantic data) set within FreeCAD.

Parametric models and related data of the Domus Regia can be reviewed by collaborators by selecting BCF (BIM Collaboration Format) option which allows to point issues out and request revised version of models (Figure 12).

This possibility is crucial, since accessibility and collaborations are the focus of the project. Models and related information have been opened to other collaborators and partners in order to enable revisions and updates on this data. This operation has been performed also by managing invitation tool of BIMData platform and setting collaboration roles (Admin, User, Guest). Furthermore, thanks to the upload system of BIMData, the web platform has been enriched by PDFs, images and datasheets related to external semantic data of the Fanum / Sacraria. This feature proves to be fundamental in order to compare and cross check the $3 \mathrm{D}$ model to $2 \mathrm{D}$ data, as well as to make all data available to collaborators.

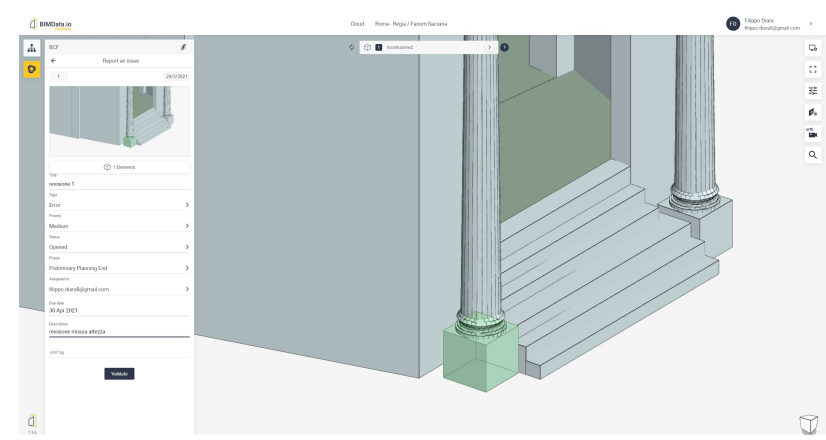

Figure 12. BCF option: example of a request of a revision regarding height measurements related to the column base.

Finally, an experimental and advanced management occurred inside ARK-BIM (https://ark-bim.github.io), an ad-hoc web platform developed on the basis of BIMData thanks to FOSS development tools (JavaScript, VueJS, XEOKIT and HTML) and plugin implementation (Diara et al., 2021). This new platform, that is under latest development tests, has been designed for the purpose of adapting a web BIM platform to archaeological domain. In fact, in addition to all BIMData features, it includes different plugins like: isolate elements; hotspot model; stratigraphic unit annotation; measurement center, 2D-3D switch and other functionalities (Figure 13).
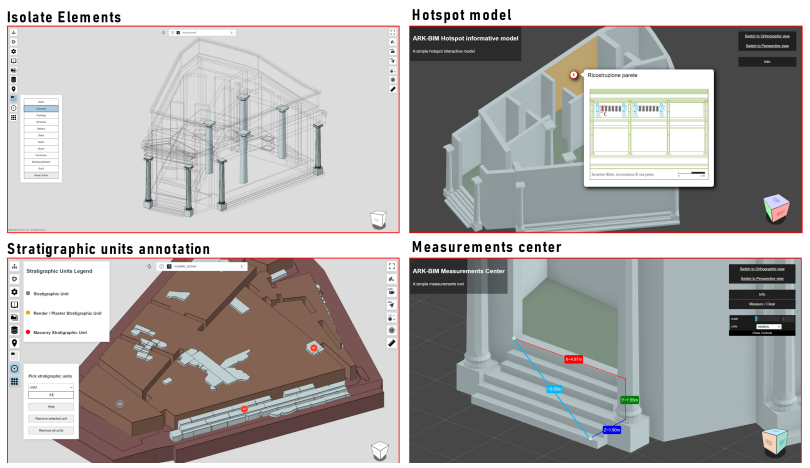

Figure 13. ARK-BIM main features: isolate elements; hotspot model; stratigraphic unit annotation; measurement center.

Through these cloud platforms an immersive collaboration can be easily handle, including a deep data accessibility for different levels of audience. Metric and semantic knowledge are preserved and enhanced at the same time.

\section{RESULTS}

The creation of an open HBIM platform for the Domus Regia and its data was the initial aim of this still in working project. This goal has been led by the willingness of increasing data accessibility, revisions and collaborations. 
Through the FreeCAD platform this has been possible, especially by including semantic information to parametric objects related to the religious building, both the excavated situation (archaeological model) and the hypothetical reconstruction.

This project could not exclude the use of cloud and web platforms for sharing knowledge. In this regard, BIMData powerful platform reveals fundamental for deep reviews and collaborations. Then, thanks to ARK-BIM custom web platform an advanced data management occurred. Both solutions allow to increase the accessibility and the enhancement potential.

This initial HBIM project could become the basis of deeper studies, allowing to implement the semantic sphere depending on updated researches. Then, it can be combined with GIS documentation already performed.

Looking at the involvement aspect, more interactive analyses could be performed by using actual VR (virtual reality) and AR (augmented reality) methodologies in order to increasingly emphasise the informative model, reaching a great level of immersion as well as remote accessibility (Diara et al., 2021). In fact, different studies are going towards mixed reality (VR and AR) implementation, encouraging professional to work together inside a smart and immersive environment (Banfi et al., 2020)

\section{CONCLUSION}

In recent years we have seen how HBIM approach can be decisive in many archaeological projects, especially to enhance even more the value of the data and researches. At the same time, FOSS instruments once again prove to be reliable and operative, including cloud data sharing and exchange possibilities.

For this reason, this project and collaboration between different academic figures rely on what BIM methodology can offer to archaeological analyses performed on the Domus Regia, in order to enrich documentation and enhancement possibilities. In fact, data fragmentation should not be a documentation problem for Heritage assets since smart informative platforms like BIM succeed in ensuring the management of different semantic information (Figure 14).

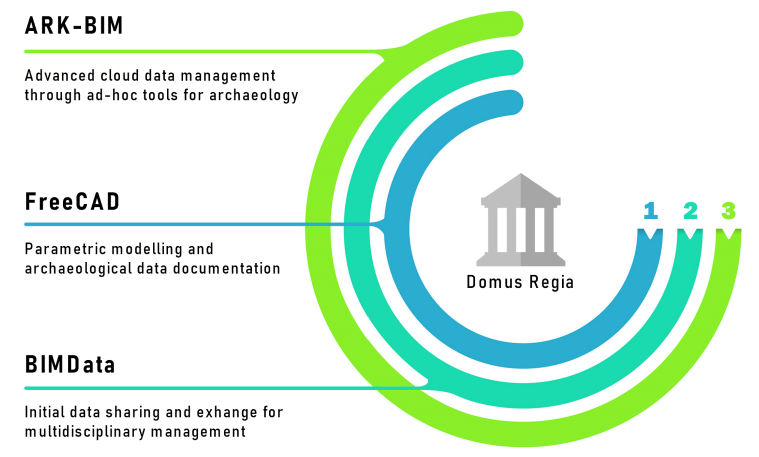

Figure 14. Data documentation and management via open source HBIM solutions occurred for the Domus Regia

Doing research nowadays should mean merge methodologies and information in order to achieve constructive collaborations among partners and professional figures. Then, data exchange through web platform is therefore fundamental for spreading technical and attractive knowledge. Finally, updates of Domus Regia data will be always possible through these informative platforms.

\section{ACKNOWLEDGEMENTS}

This work was inspired by the guidelines of the International Committee of Architectural Photogrammetry (CIPA), the scientific committee of ICOMOS, concerning Cultural Heritage documentation and preservation through the utilization of open source solutions for the correct data dissemination, idea also adopted by the GAMHer project (PRIN 2015-2020), who supported and shared this thought.

A heartfelt thanks goes to Paolo Carafa and his research team of Sapienza University of Rome for collaborating on this project, especially regarding the Domus Regia data sharing, fundamental for the HBIM platform data integration. For this reason, another special thank goes to Michela Sediari (Parco Archeologico del Colosseo) and Fulvio Rinaudo (Politecnico di Torino - DAD department) for creating this academic network.

\section{REFERENCES}

ARK-BIM. 2021. A custom cloud BIM platform for archaeology. Accessed on June 29, 2021, from https://arkbim.github.io/

Banfi, F., 2019. HBIM generation: extending geometric primitives and BIM modelling tools for heritage structures and complex vaulted systems. In: Int. Arch. Photogramm. Remote Sens. Spatial Inf. Sci., Volume XLII-2/W15, 139-148, https://doi.org/10.5194/isprs-archives-XLII-2-W15-139-2019, 2019.

Banfi F., Oreni D., Bonini A. J., 2020. The Arch of Peace of Milan and its historic memory: from 3D survey and HBIM to mixed reality (VR-AR). In: Connecting. Drawing for weaving relationships. Proceedings of the 42th International Conference of Representation Disciplines Teachers. Milano: FrancoAngeli, pp. 1660-1677.

BIMData Platform. 2021. The BIM collaborative platform of BIMDATA.IO. Accessed on June 29, 2021, from https://bimdata.io/

Brumana, R., Della Torre, S., Previtali, M., Barazzetti, L., Cantini, L., Oreni, D., Banfi, F., 2018. Generative HBIM modelling to embody complexity (LOD, LOG, LOA, LOI): surveying, preservation, site intervention-the Basilica di Collemaggio (L'Aquila). Applied Geomatics. 10. 10.1007/s12518-018-0233-3.

Bruno, N., Roncella, R., 2019. HBIM for Conservation: A New Proposal for Information Modeling. In: Remote Sensing; 11 (15), 1751. https://doi.org/10.3390/rs11151751

Carandini A., Carafa P., 2017a. The Atlas of Ancient Rome: Biography and Portraits of the City. Princeton Univ. Press, 2017. ISBN 10: 0691163472

Carandini A., Carafa P., D’Alessio M. T., Filippi D., (edited by) 2017b. Santuario di Vesta, pendice del Palatino e Via Sacra. Scavi 1985-2016. Roma 2017, Edizioni Quasar. ISBN: 978-887140-804-0

Croce V., Caroti G., Piemonte A., Bevilacqua M. G., 2021. From survey to semantic representation for cultural heritage: the 3D modelling of recurring architectural elements. In: Acta IMEKO, vol. 10, no. 1, article 13, March 2021, identifier: IMEKO-ACTA-10 (2021)-01-13 
Diara, F., Rinaudo, F., 2019. From reality to parametric models of Cultural Heritage assets for HBIM. In: The International Archives of the Photogrammetry, Remote Sensing and Spatial Information Sciences; Volume XLII-2, pp. 413-419.

Diara, F., Rinaudo, F., 2020. Building Archaeology documentation and analysis through open source HBIM solutions via NURBS modelling. In: The International Archives of the Photogrammetry, Remote Sensing and Spatial Information Sciences. Volume XLIII-B2 (2020): 1381-1388. https://doi.org/10.5194/isprs-archives-XLIII-B2- 2020-13812020

Diara, F., Rinaudo, F., 2021. Cloud data sharing and exchange of HBIM projects for archaeology: possible solutions and proposals. Proceedings of the joint international event 9th ARQUEOLÓGICA 2.0 \& 3rd GEORES, 491-494. Valencia (Spain). 26-28 April 2021

Fai, S., Rafeiro, J., 2014. Establishing an appropriate level of detail (LoD) for a building information model (BIM) - West Block, Parliament Hill, Ottawa, Canada. ISPRS Annals of the Photogrammetry, Remote Sensing and Spatial Information Sciences, 2(5), pp.123-130

Logothetis, S., Karachaliou, E., Valari, E., Stylianidis, E., 2018. Open source cloud-based technologies for BIM. In: The International Archives of the Photogrammetry, Remote Sensing and Spatial Information Sciences; Volume XLII-2, 607-614.

Messaoudi, T., Véron, P., Halin, G., De Luca, L., 2018. An ontological model for the reality-based 3D annotation of heritage building conservation state. In: Journal of Cultural Heritage. Vol. 29, pp.100-112. 2018

Murphy, M., McGovern, E., Pavia, S., 2009. Historic building information modelling (HBIM). Structural Survey 27 (4), 311 327.

Murphy, M., McGovern, E., Pavia, S., 2013. Historic Building Information Modelling - Adding intelligence to laser and image based surveys of European classical architecture. ISPRS Journal of Photogrammetry and Remote Sensing, 76, 89-102.

Quattrini R., Pierdicca R., Morbidoni C., 2017. Knowledgebased data enrichment for HBIM: exploring high-quality models using the semantic-web. J. Cult. Herit. 28 (2017) pp. 129-139.

Sammartano G., Previtali M., Banfi F., 2021. Parametric generation in HBIM workflows for slam-based data: discussing expectations on suitability and accuracy. Proceedings of the joint international event 9th ARQUEOLÓGICA 2.0 \& $3 \mathrm{rd}$ GEORES, 374-388. Valencia (Spain). 26-28 April 2021.

Trizio, I., Savini, F., Giannangeli, A., Boccabella, R., and Petrucci, G., 2019. The archaeological analysis of masonry for the restoration project in HBIM. In: The International Archives of the Photogrammetry, Remote Sensing and Spatial Information Sciences; Volume XLII-2/W9, 715-722. 